\title{
Lineamentos de um direito transnacional a partir da teoria da hegemonia de Antonio Gramsci
}

Moisés Alves Soares*

\section{HEGEMONIA E PODER RELACIONAL: PARA ALÉM DO ESTADO- NAÇÃO}

A questão do delineamento do poder de Estado e suas intersecções/ relações com a sociedade civil é das temáticas mais espinhosas, tendo em seu leito, rios de tinta escritos. Durante todo pensamento "moderno", a centralidade de análise se encontrava numa dicotomia, não meramente metodológica, entre o Estado, enquanto instituição repressiva que concentrava o poder público, e a sociedade civil, concebida como a esfera dos interesses privados e particulares. Em que pese os diferentes matizes ideológicos, desde Maquiavel a Marx, todas as teorias possuíam o mesmo problema de investigação, que era compreender como se estrutura (legitimamente ou não) o predomínio/dominação do Estado frente à sociedade civil ou mesmo as possiblidades de sua autonomia e resistência.

O pensamento de Marx, em relação a esta problemática, inaugura uma tradição ontonegativa da politicidade ${ }^{1}$, isto é, o Estado, enquanto a grande expressão moderna da política, trata-se de uma forma social histórica e transitória, que põe em marcha a reprodução e o estranhamento engendrados pelas forças sociais no conflitual mundo do capital. Nesse sentido, a política opera a alienação da vontade dos sujeitos, expressada num suposto interesse coletivo cristalizado no Estado como "uma forma autônoma, separada dos reais interesses singulares e gerais e, ao mesmo tempo, como comunidade ilusória” ${ }^{2}$. Em tal análise, portanto, a grande arquitetura da manutenção da produção capitalista seria construída pela forma estatal e resguarda pelos seus aparatos repressivos.

\footnotetext{
* Doutor em Direito do Estado pelo Programa de Pós-Graduação em Direito da Universidade Federal do Paraná (UFPR). Mestre em Teoria e Filosofia do Direito pelo Curso de Pós-Graduação em Direito da Universidade Federal de Santa Catarina (UFSC). Professor integral do Curso de Graduação em Direito da UNISOCIESC e Coordenador dos cursos de Especialização em Direito na ACE/FGG. Membro da Secretaria Executiva do Instituto de Pesquisa Direitos e Movimentos Sociais (IPDMS).
}

RDUNO, v. 2, Jan-Dez/2019 - pag (309-329) 
A incompreensão dessa negatividade ontológica, reduzindo-a a negatividade funcional, acabou por implicar uma crítica às limitações do pensamento marxista para compreensão das relações de poder contemporâneas. Nesta linha, posição emblemática é de Foucault, para quem o poder encontra-se enredado nas relações sociais e não centralizado na repressão do estado. Nesse sentido, para sua teoria do poder, "temos que deixar de descrever sempre os efeitos do poder em termos negativos: ele 'exclui', 'reprime', 'recalca', 'censura', 'abstrai', 'mascara', 'esconde'. Na verdade, o poder produz realidade, produz campos de objetos e rituais da verdade. $\mathrm{O}$ indivíduo e o conhecimento que dele se pode ter se originam nessa produção"3.

Há uma redução de Foucault em relação ao pensamento marxista, já observada por Poulantzas ${ }^{4}$, entre poder e os aparelhos de Estado. O filósofo francês trabalha, visualizando tal concepção também no marxismo, com uma definição jurídica e limitada de Estado. Por este motivo, todo o enraizamento do poder em sua positividade estaria fora do Estado e observado relacionalmente na produção dos sujeitos. Contudo, apesar da inegável potencialidade da teoria foucaultiana, Gramsci antes já construira uma teoria do poder relacional a partir do eixo explicativo da "hegemonia", que não negligencia a articulação entre a "docilidade do poder" e o seu caráter estruturalmente dirigido pelo Estado, neste caso, em seu sentido ampliado.

O marxista italiano, portanto, constrói uma teoria da hegemonia, que permite integrar tanto uma crítica ontonegativa da política em um sentido restrito - o horizonte de extinção dessa forma social constitutiva do capitalismo -, quanto uma análise ampliada de seu funcionamento estruturada com base na dialética entre a construção ideológica de consensos e o recurso à violência. O poder "privado" e poder "público" operam dialeticamente estruturados em blocos hegemônicos, tendencialmente supranacionais, para reprodução das relações sociais.

É, justamente, essa articulação hegemônica entre o privado e o público encadeada historicamente numa dinâmica interestatal e supraestatal, que se expressa de forma desigual no processo de transnacionalização do capital, o objeto de estudo deste trabalho. Por óbvio, essas breves linhas não almejam compreender todo esse processo pelas lentes gramscianas, mas indicar alguns elementos da transfiguração do direito com essa nova configuração dos mercados a partir da ascensão do neoliberalismo.

\section{A LUTA HEGEMÔNICA POR "MERCADOS DETERMINADOS" ENQUANTO EXPRESSÃO DA "CLASSE CONCRETAMENTE MUNDIAL"}

Em Gramsci, como já presente em Marx, os polos do público/privado consubstanciados nas categorias de Estado e Sociedade Civil passam por uma reflexão crítica, que reinventam elementos de sua matriz teórica. Trata-se, na 
verdade, de um redimensionamento dessa relação sobre a égide do Estado Integral ou Ampliado, isto é, Estado e sociedade civil são entendidos num nexo unidadedistinção - unidade real e distinção metodológica - sob a hegemonia do Estado.

Nos Cadernos do Cárcere, esses novos tentáculos do Estado apontam, conforme Guido Liguori ${ }^{5}$, para a esfera da economia e da sociedade civil. Nesse sentido, Liguori vê tal "ampliação" do Estado em duas grandes direções: 1) um redimensionamento da relação entre política e economia - que será discutida a seguir; 2) uma ressignificação das categorias e da relação entre sociedade política (repressão) e sociedade civil (consenso) a partir da formulação da teoria da hegemonia - alvo de estudo do ponto seguinte.

O primeiro ponto é absolutamente importante, pois, não raras vezes, temse uma afirmação do pensamento gramsciano apesar de Marx, quando não contra Marx, em especial, no que se refere ao tratamento dado à relação entre estrutura e superestrutura. Isso ocorre, pois o dito teórico das superestruturas desenvolve de forma tão ampla e criativa os nexos das relações de poder deixadas por Marx, de modo que muitos de seus intérpretes atribuem um politicismo idealista a sua teoria da hegemonia.

No entanto, Gramsci constrói sua filosofia da práxis, indubitavelmente, no seio da tradição marxista. Nos Quaderni, está expresso que o "Estado não produz ut sic a situação econômica, mas é a expressão da situação econômica" e, mais, que "o Estado só é concebível como forma concreta de um determinado mundo econômico, de um determinado sistema de produção, disso não deriva que a relação de meio e fim seja facilmente determinável e assuma o aspecto de um esquema simples e óbvio à primeira vista"7. O marxista sardo indica, então, um caráter constitutivo da relação dialética entre economia e política para constituição do modo de produção capitalista, uma vez que "estrutura e as superestruturas formam um "bloco histórico", isto é, o conjunto complexo e contraditório das superestruturas é o reflexo do conjunto das relações sociais de produção"”.

Nesse sentido, ao analisar o mundo da produção, Gramsci defende estudar as leis tendenciais do mercado nas bases de uma economia política crítica9 ${ }^{9}$. Os seus lineamentos devem ser buscados "no desenvolvimento da burguesia como 'classe concretamente mundial' e, portanto, na formação do mercado mundial já bastante 'denso' de movimentos complexos, para que dele se possam isolar e estudar as leis de regularidades necessárias [...], ou seja, a partir delas verificar o 'mercado determinado', que consiste em ambiente organicamente vivo e vinculado em seus momentos de desenvolvimento" ${ }^{10}$.

Então, ao contrário do conceito de mercado determinado constituído pela economia pura, entendido como uma abstração arbitrária e com um valor convencional, compreende-se enquanto "o conjunto das atividades econômicas concretas de uma forma social determinada, assumida em suas leis de uniformidade, isto é, uma forma abstrata, mas sem que a abstração deixe de ser historicamente determinada"11. Em mais uma síntese, salientando a imbricação 
ontológica entre o momento objetivo e subjetivo (bloco histórico), Gramsci arremata que a categoria “'mercado determinado' equivale, portanto, a dizer 'determinada relação de forças sociais em uma determinada estrutura do aparato de produção, relação esta garantida (ou seja, tornada permanente) por uma determinada superestrutura política, moral e jurídica" ${ }^{12}$. Sendo assim, para Luigi Cavallaro, "Gramsci funda uma teoria da imanência capaz de avistar, no presente histórico, a coexistência de 'mercados determinados', de modos de produção diferentes, cada um em luta contra o outro para conseguir a hegemonia"13.

Aqui, chega-se a um ponto fundamental, pois, em virtude da claríssima negação da economia como único fator determinante na conformação de um bloco histórico e salientar o papel decisivo dos contornos das relações "superestruturais", operou-se uma inversão subjetivista do pensamento gramsciano. Esta apreensão é de uma rotação de tamanha magnitude que Gramsci figura, para alguns, como um teórico da política precursor/constituinte da centralidade da linguagem na luta intersubjetiva (um liberal/protohabermasiano ${ }^{14}$ ou um radical pós-moderno/ culturalista ${ }^{15}$ ). Em suma, alguém que está além das fronteiras do marxismo.

Como visto até agora, isto se trata de um brutal equívoco, uma vez que o revolucionário sardo, por meio de sua análise do mercado determinado, buscava no solo da crítica da economia política marxiana o amparo categorial para compreender a contraditória sociedade italiana. E, embora sua abordagem do fenômeno linguístico seja um elemento constitutivo e catalizador das potencialidades da teoria geral da hegemonia gramsciana, o pulsar de suas reflexões está ancorada nas relações derivadas do trabalho, quer dizer, em que pese o seu arsenal de criativas categorias mais representativas esteja situado na esfera política, não é possível esquecer que se está a teorizar uma crítica da economia política e, portanto, compreender as dimensões do poder significa elucidar como se coloca em marcha as diferentes formas de exploração do trabalho. E, como não poderia deixar de ser, a teoria da mais-valia ou do mais-valor, que explica a produção e reprodução do capital através da extração de trabalho vivo em escala mundial, é um pilar sempre presente implícita ou explicitamente na condução dos estudos gramscianos.

Então, quando se fala em mercado determinado, não está se falando em leis naturais ou metafísicas, mas sim em seu caráter tendencial no contexto histórico-concreto. É necessário, portanto, formular qual é a tendência principal de uma situação histórica - que assume o aspecto de momento predominante ${ }^{16} \mathrm{ou}$, nas palavras de Gramsci, "a tendenciosidade converte-se em uma característica organicamente relevante", em detrimento a outras contratendências conjunturais na complexidade do mundo econômico.

Embora o conceito de mercado determinado possua características demarcadamente nacionais, sobretudo, na configuração das forças sociais componentes do campo da produção e no enraizamento das relações políticas e culturais, as classes dirigentes para aprofundar as contratendências da queda 
da taxa de lucro visam incrementar as condições de influência ou mesmo anexar outros mercados determinados ("zonas coloniais" ou economias periféricas e dependentes). Assim, Gramsci compreende que "todo grupo dirigente tende, em abstrato, a ampliar a base da classe trabalhadora da qual extrai mais-valor, mas a tendência abstrata transforma-se em concreta e imediata, quando a extração de mais-valia em sua base histórica se torna difícil ou perigosa para além de certos limites" ${ }^{17}$. Então, apesar desta questão não se construir num determinismo economicista, o marxista sardo vê a "origem das guerras" através do pano de fundo de disputas de classes dirigentes nacionais por outros "mercados determinados". $\mathrm{E}$, de certo modo, colocando a questão centro-periferia e da dependência, afirma que "em um Estado a história é a história das classes dirigentes, assim, no mundo, a história é a história dos Estados Hegemônicos. A história dos Estados subalternos se explica pela história dos Estados hegemônicos"18.

Nesse sentido, além desse movimento de forças militares ou mesmo submeter no plano político os setores dirigentes de Estados subalternos para ampliar o seu mercado determinado, a classe dirigente tende a utilizar-se do potencial legislativo de modo a conformar juridicamente outras possibilidades de intensificação de sua capacidade de extrair mais-valor. Contudo, ressalta Gramsci, que o "meio mais eficaz dos empresários, individualmente, para escapar da lei de queda é o de introduzir incessantemente novas modificações progressivas em todos os campos do trabalho e produção, sem esquecer que aportes mínimos em empresas muito grandes, multiplicados em grande escala, dão resultados muito apreciáveis" "19. É a partir deste princípio que Gramsci, no contexto da crise mundial, analisa as modificações no campo produtivo introduzidas pelo americanismofordismo, que "significa uma luta continua, incessante, para escapar da lei da queda da taxa de lucro, mantendo uma posição de superioridade sobre seus competidores" ${ }^{20}$. E, por outro lado, apesar de não enxergar no corporativismofascista um fenômeno de mesma estirpe, mas sim de um impulso à reconstituição o padrão de acumulação capitalista, uma vez que a "orientação corporativa não teve origem nas exigências de uma transformação das condições técnicas da indústria e nem sequer em uma nova política econômica, mas nas exigências de uma política econômica, exigências agravas pela crise de 1929 e ainda em curso" ${ }^{21}$.

\section{A AMPLIAÇÃO DO ESTADO PELA TEORIA DA HEGEMONIA}

A reconfiguração do conceito de Estado empreendida por Gramsci é sinuosa e fragmentada e a reconstituição do caminho trilhado até a compreensão de Estado Integral não é tarefa simples. Essa nova constituição da noção de Estado, como já foi referido, Gramsci conceitua explicitamente no Caderno 6, quando, em grande ensaio geral, afirma a necessidade para a práxis política de compreender o estado como ele realmente é "no sentido integral: ditadura + hegemonia"22.

Nesta via, ressignificando o conceito de Estado para além das suas características repressivas, Gramsci deixa uma pista germinal, desenvolvida 
por Buci-Glucksmann, ao defender uma compreensão de todos "os elementos constitutivos do Estado em um sentido orgânico e mais amplo [largo] (Estado propriamente dito e sociedade civil) "23. A partir deste trecho, a marxista francesa cunha o termo que, inexiste no léxico dos Quaderni, mas incorporou-se tão intensamente, que é atribuído automaticamente ao próprio Gramsci: Estado Ampliado. Essa "ampliação do Estado passa portanto por uma incorporação da hegemonia e de seu aparelho ao Estado. [...] A problemática da ampliação do Estado será envolvida na de correlação de forças, e a sociedade civil será atravessada, do econômico ao ideológico, pela luta de classes" 24 .

A reflexão de Gramsci, elaborando um potentíssimo estudo da ideologia e dos intelectuais, vai à direção de responder a fissura nacional e internacional causada pela revolução russa e pelas inúmeras insurreições (frustradas, mas que deixam marcas) europeias. O alargamento do estado, embora abra possibilidades, para Gramsci, não é o resultado de um processo democratização do setor público e minimização da violência, mas a emergência de novas formas de resistência a processos revolucionários.

Então, no segundo momento do alargamento do Estado, pode-se visualizar uma ampliação do Estado tanto na dimensão objetiva como subjetiva das relações sociais. Deste modo, embora com menos menções do que a alquímica utilização da metáfora arquitetônica nos Quaderni (por exemplo: Q4, \$49, Q12,\$1 e Q10, II, §15), é mais coerente a tese de Badaloni, para quem, visando a formulação da integralidade da forma estatal, Gramsci recorre "a três esferas constitutivas da realidade social, que ele denomina 'sociedade econômica', 'sociedade civil' e 'sociedade política'. Trata-se de uma distinção metodológica, porque em qualquer sociedade todos os três momentos estão presentes. A predominância de um ou de outro, ou, de qualquer maneira, a forma pela qual eles se entrelaçam constitui as marcas de uma determinada sociedade" ${ }^{25}$. No mesmo caminho, Francioni que também vê essa constituição triádica no pensamento gramsciano, ressalta que "é, portanto, errôneo relacionar, em Gramsci, a sociedade civil somente com a sociedade política, porque isto é só um aspecto da teoria gramsciana do Estado pelo qual a pesquisa do consenso se contrapõe a força-constrição" ${ }^{26}$.

No tocante a ampliação no que concerne à sociedade econômica - conceito utilizado, textualmente, em apenas duas notas (Q.10, II, \$41.VI e Q.11, §52), “mas muito mais numerosas são as passagens em que introduz termos sinônimos, como esfera produtiva, mundo produtivo, mundo da produção e similares" 27. Embora o item anterior foi bastante descritivo desse movimento, cabe ressaltar que o marxista sardo realiza, apesar do menor ineditismo, uma verdadeira crítica da economia política, na medida em que as categorias econômicas operam imbricadas com as categorias políticas em sentido lato na conformação de um mercado determinado.

Nesta relação entre a constituição da hegemonia e a conformação do mundo da produção, Gramsci confere o aspecto de momento determinante 
à sociedade econômica. A questão é que ela não poder ser entendida de forma inorgânica às outras esferas sociais sob pena de, praticamente, naturalizar uma relação social - daria razão à ideia de um Deus oculto. Assim, para o marxista sardo, "a primazia do econômico não é imediata e espontânea, mas mediada pela sociedade civil e a política" 28 .

Por sua vez, o alargamento do Estado em direção à sociedade civil com a consequente formação de um Estado Integral ou ampliado seja do arsenal categorial gramsciano, o conceito mais conhecido e mais esquematizado de forma antidialética pelos intérpretes. Uma divisão ontológica dicotômica entre sociedade política, organizadora dos aparatos repressivos e que empreende seu poder pela dominação e força, em contraposição à sociedade civil, espaço de construção de acordos (passivos e ativos) pelos aparatos "privados" via ideologia, sendo o lugar da hegemonia e dos consensos. Há que se rechaçar, de pronto, esta leitura, pois, além de filologicamente não se sustentar nos escritos gramscianos, não alcança a inovação de Gramsci em captar uma nova morfologia do Estado no interior de sua teoria geral da hegemonia.

Em geral, mesmo o conceito mais surrado para definir o Estado Integral, se transcrito em algumas linhas anteriores, não permite esta visão dual: "Estamos sempre no terreno da identificação entre Estado e Governo,[...] deve-se notar que na noção geral de Estado entram elementos que reportam a noção de sociedade civil (no sentido, que se poderia dizer que Estado = sociedade política + sociedade civil, isto é, hegemonia encouraçada de coerção" ${ }^{29}$. É possível observar que o Estado, em contraposição à visão liberal (Estado X Sociedade Civil), que, justamente, é reproduzida, forma-se da soma entre os dois elementos: uma nova forma-Estado. Assim, "Estado é todo o complexo de atividades práticas e teóricas com as quais a classe dirigente não apenas justifica e mantém o seu domínio, mas consegue obter o consenso ativo dos governados" ${ }^{30}$. Trata-se, portanto, de uma distinção metodológica, como afirma Gramsci em várias passagens, mas, evidentemente, a organicidade destes dois campos não anula a sua especificidade, legalidade interna e função predominante.

Nesse sentido, Gramsci observa na sociedade política - também se refere enquanto "Estado-governo" (Q.7,\$9), "Estado legal” (Q.7, §80), "Estado compreendido juridicamente (Q.7,\$9 e Q.10, II, \$41III), "Estado em sentido (r)estrito" (Q.26, \$6) , etc. - a um "aparato governamental-coercitivo"31 muito próximo ao exercício do poder normativo (ponto que será abordado mais a frente). Neste espaço privilegiado de constituição do poder, situa-se o espaço formalmente legítimo de atuação política representativa entre governante e governado. Há, igualmente, toda uma ossatura para absorver e manipular os conflitos sociais a fim de manter a hegemonia, bem como opera na contenção diária, mas, sobretudo, em crises orgânicas, por meio do exercício da força (legal ou ilegal). Por estes motivos, não é incorreto dizer que na sociedade política há uma função predominante de dominação de classe, contudo se faz presente também funções de direção e hegemonia - o poder executivo, legislativo e judiciário são "órgãos de 
hegemonia política"32. Afinal, as funções de governo, exercidas pelos intelectuais orgânicos ou aliados tradicionais, pressupõem, além do potencial uso da força, a atividade de construir acordos políticos, consensos sociais e até mesmo planejar mecanismos de consolidar o poder hegemônico. Ora, trata-se de um Estado Ampliado ou Integral e não uma Sociedade Civil Ampliada ou Integral.

A respeito do conceito de sociedade civil em Gramsci, há um profundo e intenso debate gerado, sobretudo, a partir da importante intervenção de Norberto Bobbio sobre o tema. O tradicional filósofo italiano faz uma constatação verdadeira, mas dela tira conclusões bastante incongruentes, isto é, que o conceito de sociedade civil de Gramsci é qualitativamente diferente de Marx - para este estaria na "estrutura" e já, no tocante àquele, seria um fenômeno "superestrutural" - e, por conseguinte, realiza uma inversão da metáfora arquitetônica marxiana. Assim, "tanto em Marx como em Gramsci a sociedade civil [...] representa o momento ativo e positivo do desenvolvimento histórico. De modo que, em Marx, esse momento ativo e positivo é estrutural, enquanto em Gramsci é superestrutural"33. Com esta interpretação, Bobbio, numa tacada só, embora negue esta conclusão, expele Gramsci da tradição marxista, transformando-o num filósofo idealista que centra suas preocupações numa teoria culturalista das superestruturas.

Tal abordagem da sociedade civil acaba por reverberar mesmo em alguns intelectuais marxistas que negam expressamente tal formulação, pois ela apimenta uma tentação liberal de confrontar a figura do Estado, com corte weberiano de portador da violência legítima, à autonomia e criatividade da sociedade civil. Mas essa leitura antimarxista de Gramsci ignora que a sociedade civil desenvolve-se em relação dialética com a sociedade política, tendo como momento predominante à constituição de uma nova morfologia de Estado. Este ponto está presente desde o Caderno 1, ainda num momento de instabilidade categorial, quando ao discutir Hegel e a experiência da revolução francesa, afirma "que os partidos e associações são como a 'trama privada' do Estado. [...] Governo com o consentimento dos governados, mas com o consenso organizado, não genérico e vago tal como se apresenta no instante das eleições" ${ }^{34}$.

O marxista sardo vai desenhando, deste modo, uma nova compreensão da sociedade civil, realmente, inédita no interior da tradição marxista e que lhe permite novos instrumentais para compreender a dinâmica da sociedade política e econômica. Para Gramsci, então, a sociedade civil, em que pese organicamente articulada, tal como os outros momentos da sociedade enquanto totalidade, encontra sua materialidade e legalidade interna nos "aparatos 'privados' de hegemonia" ${ }^{35}$. Sem dúvida, isso denota uma função predominante da produção de consensos através das "organizações ditas privadas" ou aparatos privados (sempre entre aspas para romper com qualquer acepção liberal) - igrejas, sindicatos, escolas, imprensa, etc. - pelas classes dirigentes sobre todo o povo na arena da sociedade civil. A concretização de tal "aparato hegemônico, enquanto cria um novo terreno ideológico, determina uma forma de consciências e de métodos de conhecimento” 
36. Mas, igualmente, a sociedade civil pode ser palco de manifestações de grande violência e organizações que atuam na esfera da dominação - milícias ou organizações paramilitares. Certamente, tal fato não escapou ao olhar do marxista italiano, pois sofreu na carne a ascensão conservadora do fascismo, que se apoiava em mecanismos de dominação "públicos" e "privados", entre legalidade e ilegalidade, com grande êxito político no entre guerras.

O Estado Integral ou Ampliado comporta, portanto, nas próprias palavras de Gramsci, "identidade-distinção entre sociedade civil e sociedade política e, por consequência, identificação orgânica entre indivíduos (de um determinado grupo) e o Estado" ${ }^{37}$. Por estes motivos, a sociedade política e sociedade civil são um campo aberto ou completamente entrincheirado, dependendo das determinações históricas, da luta de classes, onde não se devem naturalizar as formas de expressão do poder em cada território. "Pois, liderança-hegemonia e dominação são concebidas menos como qualitativamente distintas uma da outra do que formas estratégicas diferencias de um poder político unitário"38. Esta segunda forma de ampliação do Estado não significa um esfacelamento dos limites do Estado, se o Estado é integral, ele é também composto por suas partes distintas com suas lógicas de funcionamento próprias. E, para compreender estas esferas em sua autonomia e como parte de uma totalidade, Gramsci foca seus esforços no "delineamento da eficácia específica do Estado burguês como uma relação social e política - relações organicamente ligadas, mas que são, no entanto, distintas analiticamente para determinar sua intensidade específica e modo de produção" 39 . Por esta via, é a partir das duas ampliações acima descritas que se torna possível traçar alguns aspectos de um alargamento do direito em um cenário transnacional de luta por mercados determinados.

\section{O CENÁRIO DA TRANSNACIONALIZAÇÃO E A AMPLIAÇÃO DO DIREITO}

Para Gramsci, então, em uma das notas, que merecem maior atenção em outro espaço ${ }^{40}$, que abordam a relação entre o Estado ampliado e o direito, afirma que o "Estado é certamente concebido como organismo próprio de um grupo destinado a criar as condições favoráveis à expansão máxima desse grupo, mas este desenvolvimento e esta expansão são concebidos e apresentados como a força motriz de uma expansão universal, de um desenvolvimento de todas as energias 'nacionais', isto é, o grupo dominante é coordenado concretamente com os interesses gerais dos grupos subordinados e a vida estatal é concebida como contínua formação e superação de equilíbrios instáveis (no âmbito da lei) entre os interesses do grupo fundamental e os interesses dos grupos subordinados, equilíbrios em que os interesses do grupo dominante prevalecem, mas até um determinado ponto, ou seja, não até o estreito interesse econômico-corporativo" 41. Aqui, demonstra-se como o âmbito da lei possibilita a superação de "equilíbrios instáveis" por meio do aparato repressivo ou consensual e, da mesma forma, 
demonstra como o direito possui uma lógica própria de funcionamento na totalidade social.

Uma primeira questão que se coloca é se a teoria do Estado ampliado implica em "alargamento" da teoria do direito também. O marxista italiano em importante nota afirma que a 'Questão do 'direito', cujo conceito deverá ser ampliado, nele incluindo aquelas atividades que hoje são compreendidas na fórmula 'indiferente jurídico' e que são de domínio da sociedade civil, que atua sem 'sanções' e sem 'obrigações' taxativas, mas que nem por isso deixa de exercer uma pressão coletiva e de obter resultados objetivos de elaboração nos costume, nos modos de pensar e de atuar, na moralidade, etc" ${ }^{42}$.

Mas a que se refere esse conceito de direito que deverá ser ampliado? O revolucionário sardo fala de "uma concepção do direito que deve ser essencialmente renovadora. Ela não pode ser encontrada, integralmente, em nenhuma doutrina preexistente [...]. Se o Estado tende a criar e a manter certo tipo de civilização e de cidadão ( e, portanto, de conivência e de relações individuais), tende a fazer desaparecer certos costumes e atitudes e a difundir outros, o direito será o instrumento para esta finalidade ( ao lado da escola e de outras instituições e atividades) e deve ser elaborada para ficar conforme a tal finalidade, ser maximamente eficaz e produtor de resultados positivos" ${ }^{\prime 3}$. Por esta via, Gramsci, embora não desconsidere uma tradição secular da cultura jurídica, estabelece que as novas mediações sociais, se forem jurídicas, devem assumir outra morfologia e modo de funcionamento.

O direito, claramente, não estava reduzido ou nem mesmo determinado no campo da repressão - entendido como uma peça do Estado em sentido estrito, mas também enquanto produtor de consensos, engendrando o poder hegemônico. Assim, "em termos gramscianos, o sistema legal é um bloco complicado, isto é, que envolve por um lado o elemento do uso da força, da violência, da coerção direta e a opressão não mediada de pessoas contra outras pessoas. [...] Há, também, com a mesma importância, o papel da hegemonia" ${ }^{44}$. Esta questão de positividade do poder pelo direito, para Gramsci, “contém in nuce todo o 'problema jurídico', isto é, o problema de assimilar todo o grupo à fração mais avançada do grupo: é um problema de educação das massas, de sua 'conformação' segundo as exigências do fim a alcançar. Esta é precisamente a função do direito no Estado e na sociedade; através do 'direito', o Estado torna 'homogêneo' o grupo dominante e tende a criar um conformismo social que seja útil à linha de desenvolvimento do grupo dominante" 45 .

O tal "direito ampliado" em Gramsci pode ser encontrado nessa definição que redimensiona o direito para além do Estado em sentido estrito: "a atividade geral do direito (que é mais ampla do que a atividade puramente estatal e governativa e também inclui a atividade diretiva da sociedade civil, naquelas zonas que os técnicos de direito chamam de indiferença jurídica, isto é na moralidade e no costume em geral) serve para compreender melhor, concretamente, o problema 
ético, que na prática é a correspondência 'espontânea e livremente aceita' entre os atos e as omissões de cada indivíduo, entre a conduta de cada indivíduo e os fins que a sociedade se propõe como necessários, correspondência que é coercitiva na esfera do direito positivo tecnicamente entendido e é espontânea e livre (mais estritamente ética) naquelas zonas em que a coação não é estatal, mas de opinião pública, de ambiente moral, etc" ${ }^{" 4}$.

Há, portanto, na ampliação realizada por Gramsci do Estado e do direito, um redimensionamento do debate da configuração do poder na sociedade capitalista. Essa modificação do entendimento da dinâmica e significação entre Estado e Sociedade civil ocorreu em virtude do desenvolvimento de uma sociedade civil rica em complexidades, transfigurando, assim, a forma de controle social: a construção consensual por meio da hegemonia. O solo de tal teorização a respeito do Estado Ampliado é a forma de Estado-Nação. Com o aprofundamento do fenômeno da globalização em todas as esferas da sociabilidade, é necessário observar, em breves indicações, como se deu essa transformação dos nexos concretos do Estado e o alargamento do Direito a partir do poder hegemônico do capital em esfera transnacional.

O fenômeno da globalização reconfigura, qualitativamente, o cenário da estruturação da modalidade do capitalismo contemporâneo, realizando uma transformação no padrão de acumulação do capital, que passa por um rearranjo das relações entre economia, espaço, política e território. “Tais relações não se referem apenas à criação de uma nova forma de organização do trabalho e do capital, mas também à formação de novos pactos e consensos entre capitalistas e trabalhadores, já que o controle do capital não incide somente na extração da mais-valia, mas implica, ainda, o consentimento e adesão das classes à nova ideologia" ${ }^{47}$. A simbiose entre globalização e neoliberalismo não demora a acontecer nas economias dependentes em particular.

O signo hegemônico da globalização se expressa, portanto, no neoliberalismo, em seu imperativo econômico e cultural da liberalização dos mercados, que pode ser compreendido como um "plano teórico de reorganização do capitalismo internacional ou como um projeto político de restabelecimento das condições de acumulação do capital e de restauração do poder das elites econômicas" ${ }^{\prime 8}$. Seus elementos centrais encontram-se nos ajustes econômicos expressados na estratégia global de privatização e da supremacia do mercado -, na constituição de uma cultura antiestatal sob a égide da competência gerencial privada e na exaltação da sociedade civil em detrimento dos mecanismos de participação democráticos.

Nesse sentido, anteriormente a intensificação desse processo de globalização, Gramsci observara o americanismo/fordismo como um bloco histórico, que daria nova expressão a racionalidade do capital do século XIX. Nasce uma hegemonia da fábrica, isto é, uma reorganização do mundo produtivo, mas que, igualmente, rearticula culturalmente toda a reprodução da vida do 
trabalho. É necessária, além das alternações na esfera econômica, uma "mutação das condições sócias e dos costumes e dos hábitos individuais, que não pode ocorrer somente com a coerção, mas somente com a moderação da coação (autodisciplina) e da persuasão" ${ }^{49}$.

A transformação provocada pelo americanismo/fordismo implicou em um equilíbrio assimétrico entre capital e trabalho expressado no Estado de bemestar social de alguma maneira ou em formas compensatórias de salário indireto ao menos. Uma estruturação de uma economia de produção e consumo de massas, com pleno emprego, ampla seguridade social, que encontra, justamente, sua crise orgânica com o fenômeno da globalização neoliberal.

O cenário muda. Se antes havia um Estado Ampliado baseado num consentimento estruturado a partir de uma economia política keynesiana com um importante leque de direitos sociais e garantias públicas, tais pressupostos começam a ruir. Assim, o direito possuía uma função de extenso regulador das relações de trabalho e da circulação de capital no âmbito internacional. Além disso, garantia por meio de uma constituição dirigente um bem estar social aos cidadãos, uma vez que a gama de serviços públicos e universais eram extensos, sobretudo, no cenário europeu.

Com a crise progressiva de hegemonia desse modelo, insurge outro bloco histórico baseado na ascensão do trabalho imaterial, com uma produção de acumulação flexível e de caráter, eminentemente, transnacional. Esta reestruturação produtiva apoia-se em novas formas de intensificação do trabalho, como o Toyotismo; uma profunda terceirização nacional e internacional da produção; além de uma, não menos importante, precarização estrutural do trabalho: jornadas flexíveis, banco de horas, trabalho part-time, etc. Conjuntamente, como já mencionado, às transformações no campo econômico, caminham o processo de conformação hegemônica a partir da cruzada global do neoliberalismo.

O território onde se produz e realiza a hegemonia do capital, portanto, não mais se limita as fronteiras do Estado-Nação. Se não há uma pulverização de suas barreiras, encontra-se, sem dúvida, maior mobilidade tanto material quanto espiritual da produção do poder. Por este motivo, interpretações neogramscianas chegam a consideram que "não podemos falar mais de hegemonia de um Estado [nação]. A Hegemonia é exercida por grupos sociais, por classes ou frações de classes, por uma configuração social particular dessas frações e grupos" ${ }^{\text {"50 }}$.

Nesse sentido, para Robinson, a globalização cria novas formas de relações de classe transnacionais através das fronteiras e novas formas globais de reconfiguração das classes no interior dos países, regiões, cidades e comunidades locais, operando de um modo bastante distinto dos velhos padrões nacionais. "Sob a globalização, um novo fracionamento de classe, ou eixo, vem ocorrendo no cenário nacional e transnacional. Os Estados tem sido capturados pela orientação transnacional de grupos dominantes, que os usam para integrar seus países nas estruturas emergentes do capitalismo global". Sendo assim, a globalização de 
amplos setores e a interconexão produtiva e logística em âmbito mundial deu vazão a emergência de uma classe transnacional - sepultando, em sua financeirização, as ilusões de uma burguesia nacional anti-imperialista.

Se o processo global de hegemonia adquire um caráter transnacional, o direito amplia-se também para além do Estado-Nação, embora mantenha suas principais determinações em tal forma. O poder transnacional constrói suas ferramentas de "auto-regulação" e as esferas de decisão do direito, em especial no campo econômico, devem encontrar cortes ou mesmo uma arbitragem internacional para solução eficiente de seus litígios. Esse movimento nada mais expressa do que uma manifestação de um pluralismo jurídico conservador baseada na lex mercatória - "um direito transnacional dos negócios ou, em termos mais amplos, um direito econômico" 51 .

Na década de 90, com o avanço da ideologia neoliberal, começaram a se constituir os aparelhos de hegemonia de um direito global. Evidentemente, na dinâmica da construção do poder hegemônico, acompanhando a transnacionalização das instâncias jurídicas do ponto de vista econômico, aparecem também cortes internacionais de direitos humanos.

Neste processo, foram formados "os Tribunais Penais para Iugoslávia e Ruanda - ICTY e ICTR - ou Tribunal Penal Internacional - TPI - e o Tribunal Permanente de Revisão do Mercosul”. Além disso, outros fóruns obtiveram outro caráter como "a Corte Europeia de Justiça, as Cortes Europeia, interamericana e Africana de Direitos Humanos e o Painel de resolução de Disputas da OMC. Atualmente, cento e vinte e cinco órgãos internacionais de tomada de decisão são listados pelo Projeto de Cortes e tribunais internacionais (PCTI). De forma similar, os tribunais nacionais foram trazidos de maneira mais intensa a esse sistema heterárquico de 'remédios globais', em que são tratadas questões jurídicas transnacionais do direito penal internacional para reivindicações de restituição, oriundas da violação dos direitos humanos em todo o mundo" 52.

Há, no que tange a ampliação do direito, uma tensão nesse bloco histórico neoliberal entre formalização e desregulamentação, bem como entre o transnacional e o internacional, que é identificada por Cutler enquanto uma contradição dialética entre "soft law" e "hard law".

A tensão entre "soft law" e "hard law", para Cutler, expressa os mecanismos de acumulação do capitalismo contemporâneo, pois "a 'soft law' injeta uma medida de flexibilidade ao mesmo tempo que aparenta ser lei”, isto é, "os direitos das empresas são enquadrados em formas legais exigíveis, mas os deveres corporativos são moldados em formas predominantemente legais fracas (soft) que pode ou não se consubstanciar em normas legais exigíveis [hard law]" ${ }^{53}$. Nesse sentido, tais "tensões entre a formalização e desregulamentação da lei, entre a regulação jurídica 'soft' e 'hard' e entre a legalidade internacional e transnacional sugerem a existência de incongruências profundas na ordem mundial. No entanto, essas incongruências são apenas aparentes, uma análise crítica do direito transnacional 
revela uma unidade mais profunda de propósito e design que é obscurecida por presunções de pluralismo jurídico. Porque o 'transnacional' " é ao mesmo tempo um projeto político, uma aspiração e um complexo produtivo material, institucional e ideológico, que serve a acumulação do capital transnacional" 54 .

Essas tendências identificadas do impacto da globalização neoliberal no direito ampliado pelas correntes neogramscianas aqui expostas, apesar de visualizar a grande potencialidade de conceber uma classe transnacional que opera por meio de uma transfiguração do Estado/Direito ampliado em mercados determinados, a Forma-Estado continua ainda a ser o momento fundamental da vida coletiva, ainda que submetida a processos e contradições que constantemente redefinem o seu papel. Ainda, por fim, é necessário visualizar esses espaços jurídicos hegemônicos transnacionais como inseridos nesse processo de direito ampliado dos estados nacionais, que encontram um novo momento frente ao recrudescimento dos movimentos nacionalistas e o crescimento do protecionismo no cenário de crise econômica global.

\section{NOTAS}

1 "É ontonegativa, precisamente, porque exclui o atributo da política da essência do ser social, só o admitindo como extrínseco e contingente ao mesmo, isto é, na condição de historicamente circunstancial [...] Marx assinala, categoricamente, que a emancipação é na essência a reintegração ou recuperação humano-societária dessas forças sociais alienadas à política, ou seja, que ela só pode se realizar como reabsorção de energias próprias despidas da forma política, depuradas, exatamente, da crosta política sob a qual haviam se autoaprisionado e perdido". CHASIN, José. Estatuto Ontológico e Resolução Metodológica. São Paulo: Boitempo, 2009, p.64-65.

2 MARX, Karl; ENGELS, Friedrich. A Ideologia Alemã: crítica da mais recente filosofia alemã em seus representantes Feuerbach, B. Bauer e Stirner, e do socialismo alemão em seus diferentes profetas. São Paulo: Boitempo, 2007, p.73.

3 FOUCAULT, Michel. Vigiar e punir. Petrópolis: Vozes, 1977, p. 172.

4 "O poder não é de nenhuma forma redutível ou identificável ao Estado, embora Foucault e Deleuze assim o digam do marxismo, porque o 'poder seria poder do Estado, estaria ele mesmo localizado num aparelho do Estado... e ' identificar-se-ia ao Estado' [...] enquanto para Foucault e Deleuze o Estado limita-se sempre ao núcleo público (exército polícia, prisão, tribunais, etc.) o que lhes possibilita dizer que o poder existe fora do Estado, tal como o concebem, isto é, uma série de lugares, supostos como fora do Estado (aparelho saúde-asilos, hospitais, aparelhos esportivos etc.)”. POULANTZAS, Nicos. O Estado, o poder, o socialismo. Rio de Janeiro: Edições Graal, 1980, p.42.

5 LIGUORI, Guido. Roteiros para Gramsci. Rio de Janeiro: Editora UFRJ, 2007, p.13-4.

6 GRAMSCI, Antonio. $\$ 41$ - VI. Quaderni del carcere. Edizione critica dell'Istituto Gramsci. A cura di Valentino Gerratana. Volume secondo. Quaderni 10. Turim: Giulio Einaudi, 2007, p.1310. 
7 GRAMSCI, \$61. Quaderni del carcere. Volume secondo. Quaderni 10..., 2007, p.1360.

8 GRAMSCI, \$182. Quaderni del carcere. Volume secondo. Quaderni 8..., 2007, p.1051.

9 Gramsci faz uma distinção entre três vertentes da economia política: a economia política clássica - que é, na sua visão, representada principalmente pela figura imponente de David Ricardo -, a economia política crítica - que é sua abreviação para a crítica da economia política de Marx e a economia política marxista - e a economia pura, que é, em grande parte, a mesma que a economia neoclássica ortodoxa, ainda em construção em seus dias. KRÄTKE, Gramsci and the Renewal of the Critique of Political Economy..., 2016, p.5.

10 GRAMSCI, \$9. Quaderni del carcere. Volume secondo. Quaderno 10..., 2007, p.1247-8.

11 GRAMSCI, \$32. Quaderni del carcere. Volume secondo. Quaderno 10..., 2007, p.1276-7.

12 GRAMSCI, \$52. Quaderni del carcere. Volume secondo. Quaderno 11..., 2007, p.1477, grifo nosso.

13 CAVAllaro, Luigi. A economia política de Gramsci. Novos Rumos, São Paulo, n. 38, 2002, p. 14-15.

14 "Habermas propugna, em sua análise sobre a sociedade contemporânea, que a centralidade do trabalho foi substituída pela centralidade da esfera comunicacional ou da intersubjetividade". Então, "no nível mais abstrato, a sobrevalorização habermasiana se efetiva pela perda da relação de distância e prolongamento existente entre o trabalho e a práxis interativa, que assume a forma relacional entre esferas que se tornaram dissociadas, a partir da complexificação da vida societal. [...] Habermas, ao contrário, na disjunção que opera a partir da complexificação das formas societais, conferirá à esfera da linguagem e da comunicação o espaço e o sentido privilegiado da emancipação". Quando, então, avalia-se Gramsci enquanto um teórico da constituição de alianças políticas e formação de consensos "comunicacionais" na sociedade civil, opera-se uma redução reformista e, por que não dizer, protohamermasiana do marxista sardo. ANTUNES, Ricardo. Os sentidos do trabalho: ensaio sobre a afirmação e negação do trabalho. São Paulo: Boitempo, 2009, p.146 e p.157.

15 "O pós-modernismo empurra a ótica comunista para um culturalismo desequilibrado, para um relativismo moral e para uma hostilidade aos universais". Desde modo, "se o pós-modernismo constitui uma forma de culturalismo, é porque, entre outras razões, ele se recusa a reconhecer que o que os diferentes grupos étnicos têm em comum em termos sociais e econômicos é, no final das contas, mais importante que suas diferenças". EAGLETON, Terry. As ilusões do pós-modernismo. Rio de Janeiro: Jorge Zahar, 1998, p.80-90. Portanto, nesta constelação de subjetividades, "cada indivíduo é uma combinação original de pertenças múltiplas. Mas a maior parte dos discursos da pós-modernidade faz a crítica da vulgata ortodoxa até dissolver as relações de classes nas aguas turvas do invidualismo metodológico. BENSAÏD, Daniel. Os irredutíveis: teoremas de resistência para o tempo presente. São Paulo: Boitempo, 2008, p.44. Por esta via, desenvolvem-se uma série de estudos culturais que, embora importantes, ao negar a centralidade do trabalho, centram suas baterias no terreno da ruptura discursiva com os mecanismos hegemônicos de dominação (coloniais, raciais, gênero, etc.) e negligenciam o imperativo de derrotar o mundo do capital.

16 Sobre o conceito de momento predominante, Lukács no rastro de Marx e Hegel, explica: "É claro: a interação tem muitos aspectos e se articula de diferentes modos. Mas também está claro que nessa relação entre determinações de reflexão tão ricamente articulada revela-se com toda evidência o traço fundamental da dialética materialista: nenhuma interação real (nenhuma real determinação de reflexão) existe sem momento predominante. Quando essa relação fundamental não é levada na devida conta, tem-se ou uma série causal unilateral e, por isso, mecanicista, simplificadora e deformadora dos fenômenos, ou então aquela interação carente de direção, superficialmente rutilante, cuja ausência de ideia Hegel criticou com razão em seu tempo, mas sem encontrar solução para o problema”. LUKÁCS, György. Para uma Ontologia do Ser Social I. São Paulo: Boitempo, 2012, p.232. "Traduzindo o que Hegel entendeu corretamente para a linguagem ontológica que 
ele apenas subentendeu (porque para Hegel o conceito é simultaneamente lógico e ontológico), o núcleo intencionado por ele poderia ser expresso da seguinte maneira: a simples interação levaria a um estado estacionário e, em última análise, estático; caso se queria dar expressão conceitual à dinâmica viva do ser, ao seu desenvolvimento, é preciso indicar onde, na referida interação, pode ser encontrado o momento predominante". LUKÁCS, György. Para uma Ontologia do Ser Social II. São Paulo: Boitempo, 2013, p.184.

17 GRAMSCI, Antonio. \$34. Quaderni del carcere. Edizione critica dell'Istituto Gramsci. A cura di Valentino Gerratana. Volume terzo. Quaderni I2-29 (1932-1935). Quaderno 13. Turim: Giulio Einaudi, 2007, p.1631.

18 GRAMSCI. \$5. Quaderni del carcere.Volume terzo. Quaderno 15 (II)..., 2007, p.1759.

19 GRAMSCI, \$36. Quaderni del carcere. Volume secondo. Quaderno 10..., 2007, p.1281.

20 GRAMSCI, \$36. Quaderni del carcere. Volume secondo. Quaderno 10..., 2007, p. 1282.

21 GRAMSCI. \$6. Quaderni del carcere.Volume terzo. Quaderno 22..., 2007, p.2153.

22 GRAMSCI, \$155. Quaderni del carcere. Volume secondo, Quaderno 6..., 2007, p. 810-11.

23 GRAMSCI, $\$ 87$. Quaderni del carcere. Volume secondo, Quaderno 6..., p. 763.

24 BUCI-GLUCKSMANN, Christine. Gramsci e o Estado: por uma teoria materialista da filosofia. Rio de Janeiro: Paz e Terra, 1980, p.98-110.

25 BADANOLI, Nicola. Liberdade Individual e Homem Coletivo em Antonio Gramsci. INSTITUTO GRAMSCI. Política e História em Gramsci. Vol. I. Rio de Janeiro: Civilização Brasileira, 1978, p.37.

26 FRANCIONI, Gianni. L'Officina gramsciana: ipottesi sulla struttura dei "Quaderni del carcere". Napolis: Bibliopolis, 1984, p.193.

27 FRANCIONI, L'Officina gramsciana..., 1984, p.192-3, grifos do autor.

28 BADANOLI, Nicola. Liberdade Individual e Homem Coletivo em Antonio Gramsci..., 1978, p.40.

29 GRAMSCI, $\$ 88$. Quaderni del carcere. Volume secondo, Quaderno 6..., 2007, p.763-64.

30 GRAMSCI. \$10. Quaderni del carcere.Volume terzo. Quaderno 15..., 2007, p.1765.

31 GRAMSCI, \$136. Quaderni del carcere. Volume secondo, Quaderno 6..., 2007, p.800

32 GRAMSCI, \$81. Quaderni del carcere. Volume secondo, Quaderno 6..., 2007, p.752.

33 BOBBIO, Norberto. O conceito de sociedade civil. Rio de Janeiro: Graal, 1982, p.33.

34 GRAMSCI, Antonio. $\$ 47$. Quaderni del carcere. Edizione critica dell'Istituto Gramsci. A cura di Valentino Gerratana. Volume primo. Quaderni I-5 (1929-1932). Quaderno 1. Turim: Giulio Einaudi, 2007, p.56.

35 GRAMSCI, \$137. Quaderni del carcere. Volume secondo, Quaderno 6..., 2007, p.801.

36 GRAMSCI, \$12. Quaderni del carcere. Volume secondo, Quaderno 10..., 2007, p.1250.

37 GRAMSCI, \$142. Quaderni del carcere.. Volume secondo. Quaderno 8..., 2007, p.1028.

38 THOMAS, Peter. The Gramscian Moment: philosopy, hegemony and marxism. Leiden: Boston: Brill, 2009, p.163.

39 THOMAS, The Gramscian Moment...,2009, p.191.

40 A ver: SOARES, Moisés Alves. O Direito em contraponto a partir do itinerário da teoria geral da hegemonia em Antonio Gramsci. Tese. Curitiba: UFPR, 2017.

41 GRAMSCI. \$16. Quaderni del carcere.Volume terzo. Quaderno 13..., 2007, p.1577-1578. 
42 GRAMSCI. \$11. Quaderni del carcere.Volume terzo. Quaderno 13..., 2007, p.1570.

43 GRAMSCI. \$11. Quaderni del carcere. Volume terzo. Quaderno 13..., 2007, p.1570.

44 KENNEDY, Duncan. Antonio Gramsci and the Legal System. ALSA Forum, vol. 6, 32-37, 1982, p.35.

45 GRAMSCI, \$84. Quaderni del carcere. Volume secondo. Quaderni 6.., 2007, p.756-758.

46 GRAMSCI, \$84. Quaderni del carcere. Volume secondo. Quaderni 6..., 2007, p.757.

47 SIMIONATO, Ivete. A cultura do capitalismo globalizado. Novos consensos e novas subalternidades. In:COUTINHO, Carlos Nelson; Teixeira, Andréa de Paula (Org.). Ler Gramsci, entender a realidade. Rio de Janeiro: Civilização Brasileira, 2003, p.276.

48 HARVEY, David. O neoliberalismo: história e implicações. São Paulo: Edições Loyola, 2012, p.27.

49 GRAMSCI, Antonio. Americanismo e Fordismo. São Paulo: Hedra, 2008, p.81.

50 ROBINSON, William. Gramsci and Globalisation: From Nation-State to Transnational Hegemony. Critical Review of International Social and Political Philosophy. Vol. 8, No. 4, 1-16, December 2005, p.6.

51 SOUSA SANTOS, Boaventura. La globalización del derecho: los nuevos caminos de la regulación y la emancipación. Bogotá: ILSA, Ediciones Universidad Nacional de Colombia, 1998, p.110.

52 BUCKEL, Sonja and FISCHER-LESCANO, Andreas. Reconsiderando Gramsci: hegemonia no direito global. Rev. direito GV [online]. 2009, vol.5, n.2, pp. 471-490. 482 -483.

53 CUTLER, A.C. Legal Pluralism as the "Common Sense" of Transnational Capitalism. Oñati Socio-legal Series [online], 3 (4), 719-740, 2013, p.733.

54 Ibid.p.733.

\section{REFERÊNCIAS}

ANTUNES, Ricardo. Os sentidos do trabalho: ensaio sobre a afirmação e negação do trabalho. São Paulo: Boitempo, 2009.

BADANOLI, Nicola. Liberdade Individual e Homem Coletivo em Antonio Gramsci. INSTITUTO GRAMSCI. Política e História em Gramsci. Vol. I. Rio de Janeiro: Civilização Brasileira, 1978.

BENSAÏD, Daniel. Os irredutíveis: teoremas de resistência para o tempo presente. São Paulo: Boitempo, 2008.

BUCI-GLUCKSMANN, Christine. Gramsci e o Estado: por uma teoria materialista da filosofia. Rio de Janeiro: Paz e Terra, 1980.

BUCKEL, Sonja and FISCHER-LESCANO, Andreas. Reconsiderando Gramsci: hegemonia no direito global. Rev. direito GV [online]. 2009, vol.5, n.2, pp. 471-490.

CAVAllarO, Luigi. A economia política de Gramsci. Novos Rumos, São Paulo, n. 38, 2002. 
CHASIN, José. Estatuto Ontológico e Resolução Metodológica. São Paulo: Boitempo, 2009.

COUTINHO, Carlos Nelson. Gramsci: Um estudo sobre seu pensamento político. Rio de Janeiro: Civilização Brasileira, 2012.

CUTLER, A.C. Legal Pluralism as the "Common Sense" of Transnational Capitalism. Oñati Socio-legal Series [online], 3 (4), 719-740, 2013.

EAGLETON, Terry. As ilusões do pós-modernismo. Rio de Janeiro: Jorge Zahar, 1998.

FOUCAULT, Michel. Vigiar e punir. Petrópolis: Vozes, 1977.

GRAMSCI, Antonio. Quaderni del carcere. Edizione critica dell'Istituto Gramsci. A cura di Valentino Gerratana. Volume primo. Quaderni I-5 (1929-1932). Turim: Giulio Einaudi, 2007.

GRAMSCI, Antonio. Quaderni del carcere. Edizione critica dell'Istituto Gramsci. A cura di Valentino Gerratana. Volume secondo. Quaderni 6-II (1930-1933). Turim: Giulio Einaudi, 2007.

GRAMSCI, Antonio. Quaderni del carcere. Edizione critica dell'Istituto Gramsci. A cura di Valentino Gerratana. Volume terzo. Quaderni I2-29 (1932-1935). Turim: Giulio Einaudi, 2007.

GRAMSCI, Antonio. Americanismo e Fordismo. São Paulo: Hedra, 2008

HARVEY, David. O neoliberalismo: história e implicações. São Paulo: Edições Loyola, 2012.

KENNEDY, Duncan. Antonio Gramsci and the Legal System. ALSA Forum, vol. 6, 3237, 1982.

LIGUORI, Guido. Roteiros para Gramsci. Rio de Janeiro: Editora UFRJ, 2007.

LUKÁCS, György. Para uma Ontologia do Ser Social I. São Paulo: Boitempo, 2012,

Para uma Ontologia do Ser Social II. São Paulo: Boitempo, 2013,

MARX, Karl; ENGELS, Friedrich. A Ideologia Alemã: crítica da mais recente filosofia alemã em seus representantes Feuerbach, B. Bauer e Stirner, e do socialismo alemão em seus diferentes profetas. São Paulo: Boitempo, 2007.

POULANTZAS, Nicos. O Estado, o poder, o socialismo. Rio de Janeiro: Edições Graal, 1980.

SIMIONATO, Ivete. A cultura do capitalismo globalizado. Novos consensos e novas subalternidades. In:COUTINHO, Carlos Nelson;Teixeira, Andréa de Paula (Org.). Ler Gramsci, entender a realidade. Rio de Janeiro: Civilização Brasileira, 2003. 
SOUSA SANTOS, Boaventura. La globalización del derecho: los nuevos caminos de la regulación y la emancipación. Bogotá: ILSA, Ediciones Universidad Nacional de Colombia, 1998.

ROBINSON, William. Gramsci and Globalisation: From Nation-State to Transnational Hegemony. Critical Review of International Social and Political Philosophy. Vol. 8, No. 4, 1-16, December 2005.

Submetido: 05/05/2020. Aceito: $15 / 05 / 2020$. 


\section{Lineamentos de um direito transnacional a partir da teoria da hegemonia de Antonio Gramsci}

\section{Resumo}

O pensamento de Antonio Gramsci pode, mesmo em linhas gerais, dar elementos para compreender o alargamento do direito frente ao fenômeno da transnacionalização. A teoria da hegemonia comporta uma crítica da economia política e do Estado capaz de compreender a emergência de uma "classe mundial" em luta por seus "mercados determinados". Além disso, ao observar o surgimento da acumulação flexível, houve uma alteração da relação entre espaço e capital, que pode ser analisada com ampliação do direito para formas transnacionais.

Palavras-chave: Gramsci; Hegemonia; Mercado Determinado; Direito Ampliado; Transnacionalização 


\title{
Aspects of a transnational law based on hegemony theory of Antonio Gramsci
}

\begin{abstract}
Antonio Gramsci's thinking can, even in general lines, provide elements to understand the widening of the law in front of the phenomenon of transnationalization. The theory of hegemony entails a critique of political economy and the State capable of understanding the emergence of a "world class" struggling for its "determined markets". $\mathrm{n}$ addition, when observing the emergence of flexible accumulation, there was a change in the relationship between space and capital, which can be analyzed by law enlargement to transnational forms.
\end{abstract}

Keywords: Gramsci; Hegemony; Determined Market; Enlargement Law; Transnationalization 